\title{
Hidden Danger: Superbug Escherichia coli lsolated from Urine Isolates of Outpatient Women with Uncomplicated Urinary Tract Infection
}

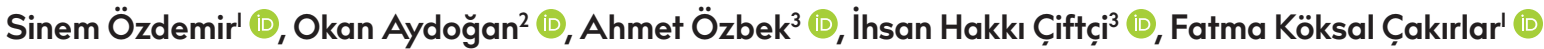 \\ 'Department of Medical Microbiology, İstanbul University-Cerrahpașa Cerrahpașa School of Medicine, i̇stanbul, Turkey \\ 2Department of Medical Microbiology, İstanbul Medipol University School of Medicine, İstanbul, Turkey \\ ${ }^{3}$ Department of Medical Microbiology, Sakarya University School of Medicine, Sakarya, Turkey
}

ORCID iDs of the authors: S.Ö. 0000-0002-2339-857l; O.A. 0000-000I-7275-8724; A.Ö. 0000-000I-8938-6533; I.H.C̣. 0000-0002-98I2I34X; F.K.C.. 0000-0003-4279-434X.

Cite this article as: Özdemir S, Aydoğan O, Özbek A, Çiftc̣i iH, Köksal C̣akırlar F. Hidden Danger: Superbug Escherichia coli lsolated from Urine Isolates of Outpatient Women with Uncomplicated Urinary Tract Infection. Cyprus J Med Sci 2020; 5(2): I0I-6.

\section{BACKGROUND/AIMS}

Escherichia coli (E. coli) is responsible for the vast majority of uncomplicated bacterial urinary tract infection (UTI) cases in women. The high ability of the isolates to develop antimicrobial resistance makes the treatment difficult. In this study, we investigated the presence of plasmid-mediated quinolone resistance (PMQR) genes in E. coliisolates and their relationship with extended-spectrum beta-lactamases (ESBL).

\section{MATERIAL and METHODS}

A total of 300 E. coliisolates from urine specimens of women, including 108 ESBL producers and 192 non-ESBL producers, were analyzed The ESBL production was examined using the E-test ESBL strips, and the carbapenemase activity was examined using the CarbaNP test. The presence of PMQR genes ( $q n r A$, qnrB, qnrS, and aac ( $\left.6^{-}\right)-l b$ ) among urine isolates was investigated using polymerase chain reaction. Conjugation experiments were performed to detect the horizontal transferability of the PMQR-positive plasmid.

\section{RESULTS}

Among the ESBL-EC isolates, ciprofloxacin resistance was determined at $69 \%$. Eight isolates were resistant to carbapenems. The aac (6')$1 \mathrm{~b}$-cr variant was found in $40 \%$ of ciprofloxacin-resistant $E$. coli isolates. None of the isolates harbored the qnrA, qnrB, or qnrS gene. The transferability was $14 \%$ for $a a c\left(6^{\prime}\right)-I b$-cr. The MICs of transconjugants showed increased resistance to fluoroquinolones compared with the recipient E. coli J53AzR.

CONCLUSION: This study showed that the frequency of PMQR genes in ESBL-producing superbug E. coli isolates reduced therapeutic options for treating community-acquired UTIs in affected women and that a careful use of antibiotics is very important.

Keywords: ESBL-producing Escherichia coli, superbug, PMQR genes, aac(6')-Ib-cr, female patients with UTI, fosfomycin

\section{INTRODUCTION}

All over the world, in outpatient practice, uncomplicated bacterial urinary tract infections (UTIs) are one of the most common community-acquired diseases. Escherichia coli (E. coli) is responsible for the vast majority of UTIs, and especially women suffer from UTIs because of the proximity of the urethra to the vagina and the rectum, changes in genital microflora, hormonal influences, and other anatomical and physiological characteristics (I). E. coli is a part of the normal flora in the intestinal tract of a healthy human. Uropathogenic E. coli is generally acquired from sexual partners, household members, pets, food, toilet, and during travel. However, the high ability of the isolates to develop antimicrobial resistance makes the treatment difficult. These bacteria can transfer the resistance genes to other $E$. coli isolates and different Gram-negative bacteria. Therefore, multidrug-resistant E. colideserves a superbug label. Furthermore, antimicrobial options in treatment are limited due to multidrug resistance (2). Quinolones are the first choice for the treatment of UTIs caused by extended-spectrum-beta-lactamase (ESBL)-producing E. coli. However, the widespread use of quinolones for therapeutic and non-therapeutic purposes has led to the rapid spread of quinolone-resistant $E$. coli isolates worldwide (3). The resistance to quinolones usually occurs as a result of "DNA target mutations, overexpression of efflux pumps, loss of porins and mobile genetic elements encoded on plasmids, known as plasmid-mediated quinolone resistance 
(PMQR) genes, namely qnr, aac (6')-lb-cr, and qepA" $(4,5)$. A series of $P M Q R$ determinants within the last 10 years further reveal a new issue about the resistance to quinolones. PMQR genes play an essential role in the development of low-level quinolone resistance and facilitate the emergence of high-level resistance in the presence of quinolones at treatment levels (6). PMQR genes, $\operatorname{qnr}($ gnrA, $q n r B$, and $q n r S$ ), which protects the DNA gyrase and Type IV topoisomerase enzymes from quinolone inhibition, and $a a c\left(6^{\prime}\right)-l b-c r$, which acetylates quinolones, and efflux by QepA and OqxAB have been reported in clinical isolates of Enterobacteriaceae, including E. coli $(3,6-8)$. In many studies, PMQR genes have frequently been shown to be associated with genes encoding ESBL and aminoglycosides on the same plasmid $(8,9)$. Today, plasmids carrying qurand ESBL determinants represent a concern worldwide. Carbapenems are often the last-choice agents used for the treatment of patients with severe infections. However, carbapenemase-producing $E$. coli has been increasingly reported, especially in clinical settings $(2,10)$. Fosfomycin, known for over 40 years, has recently become attractive as an alternative agent for the treatment of UTIs (II). "The Infectious Diseases Society of America (IDSA) recommends that physicians obtain information on local resistance rates, the appropriateness of empirical therapy proposals and that ongoing surveillance has been conducted to monitor changes in the susceptibility of uropathogens" $(12,13)$. This study aimed to investigate the presence of PMQR ( $q n r A$, qnrB, qnrS, and $\operatorname{aac}\left(6^{\prime}\right)-(b-c r)$ genes, and also their relationship to ESBL among $E$. colistrains isolated from urine samples of outpatient Turkish women, with community-acquired UTI.

\section{MATERIAL and METHODS}

\section{Methodology}

A total of 300 E. coli isolates were obtained from urine samples of outpatient Turkish women with symptoms suggestive of community-acquired UTIs in İstanbul University-Cerrahpașa, Cerrahpașa School of Medicine Hospital. In the study, the patients were aged $16-85$ years. Patients who were pregnant, with functional, or structural anomalies of the urinary tract, and suffering from an immunocompromized illness, and using immunosuppressants, and who were discharged from the hospital I0-15 days before were excluded from the study. The identification and antimicrobial susceptibility were determined using the BD Phoenix automated identification and susceptibility testing system (BD Diagnostic Systems, Sparks, MD). The isolates resistant or moderately susceptible to tested antibiotics were confirmed using the E-test (bioMerieux, France) method. The susceptibility of ciprofloxacin, carbapenems, tigecycline, colistin, and fosfomycin was determined by E-test (bioMerieux, La Balme-les-Grottes, France) method according to manufacturer's instructions. The results were interpreted according to the European Committee on Antimicrobial Susceptibility Testing (14). The ESBL production was examined using the double-ended E-test ESBL strips (AB Biodisk, Solna, Sweden) containing gradients of cefotaxime (CT) or ceftazidime (TZ) or cefepime (FEP) at one end and cefotaxime or ceftazidime or cefepime plus clavulanic acid (CTL, TZL, and FEL) at the other, according to the manufacturer's instructions. The carbapenemase activity was investigated using the Carba NP test (RAPIDEC CARBA NP (bioMerieux, La Balmeles-grottes, France) (15). Quinolone-resistant isolates were screened for the presence of PMQR ( $q n r A$, qnrB, qnrS, and aac $\left(6^{\prime}\right)-1 b$ ) genes by the polymerase chain reaction (PCR). DNA was extracted from the fresh culture of $E$. colicolonies according to the protocol performed using the GeneJET Genomic DNA Purification kit (Thermo Scientific, USA). The determination of PMQR ( $q n r A, q n r B$, qnrS, and aac ( $\left.6^{\prime}\right)-l b$ ) genes was performed using PCR. All aac ( $\left.6^{\prime}\right)-1 b$ positive amplicons were investigated by digestion with BseGI (Fermantas, USA) restriction enzyme to determine the aac ( $\left.6^{\prime}\right)$ - Ib-crvariant. The amplification of $q n r A$, $q n r B$, qnrS, and aac ( $\left.6^{\prime}\right)-1 b$ genes was performed using the primers presented in Table I $(4,9,16-18)$.

\section{Conjugation Assays Used to Detect PMQR Transferability}

Conjugation experiments were performed to detect whether the quinolone resistance could be transferred horizontally to a plasmid-free $E$. colistrain from E. coli urine isolates carrying PMQR-positive plasmids. A plasmid-free, sodium azide-resistant E. coli J53 (AzR) was used as the recipient, as described previously (19). The recipient (J53) and donor urine isolates were inoculated into the Luria-Bertani (LB) broth (Difco) and grown overnight at $37^{\circ} \mathrm{C}$. The equal volumes of the donor and recipient cultures were mixed and incubated overnight at $37^{\circ} \mathrm{C}$. The serial dilutions were homogeneously spread onto trypticase soy agar (Oxoid) plates supplemented with sodium azide ( $150 \mu \mathrm{g} / \mathrm{mL}$, Sigma-Aldrich) and ciprofloxacin $(0.25 \mu \mathrm{g} / \mathrm{mL}$, Sigma-Aldrich). The transconjugants were selected and collected on the plates. PCR was performed to determine the presence of PMQR determinants (20). Plasmid DNAs of transconjugants and donor isolates were extracted using the GenElute Plasmid Miniprep Kit (Sigma-Aldrich, Vienna, Austria) according to the manufacturer's instructions. The size of plasmid was estimated by electrophoresis using a $0.7 \%(\mathrm{w} / \mathrm{v})$ agarose gel, comparing

\begin{tabular}{|c|c|c|c|c|c|}
\hline Target gene & & Primer sequence $\left(5^{\prime} \rightarrow 3^{\prime}\right)$ & Gene size & Genebank accession No. & $\begin{array}{l}\text { Predicting the size of } \\
\text { amplicon (bp) }\end{array}$ \\
\hline \multirow[t]{2}{*}{ qnrA } & $\mathrm{F}$ & TCAGCAAGAGGATTTCTCA & 657 & KC493127.I & 627 \\
\hline & $\mathrm{R}$ & GGCAGCACTATTACTCCCA & & & \\
\hline \multirow[t]{2}{*}{$q n r B$} & $\mathrm{~F}$ & ATGACGCCATTACTGTATAA & 681 & EF634464.I & 562 \\
\hline & $\mathrm{R}$ & GATCGCAATGTGTGAAGTTC & & & \\
\hline \multirow[t]{2}{*}{ qnrs } & $\mathrm{F}$ & ACGACATTCGTCAACTGCAA & 656 & EU391634.I & 417 \\
\hline & $\mathrm{R}$ & TAAATTGGCACCCTGTAGGC & & & \\
\hline \multirow[t]{2}{*}{$a a c\left(6^{\prime}\right)-l b-c r$} & $\mathrm{~F}$ & TTGCGATGCTCTATGAGTGGCTA & 519 & Q214316.1 & 482 \\
\hline & $\mathrm{R}$ & CTCGAATGCCTGGCGTGTTT & & & \\
\hline
\end{tabular}


the known plasmid molecular size markers of E. coli $V 517$ harboring plasmids of 54.4, 7.l, 5.6, 5.2, 3.0, 2.7, and 2.I kb, as previously described (19). MICs of ciprofloxacin were determined for the

$$
\square E S B L+\quad \quad \text { ESBL- }
$$

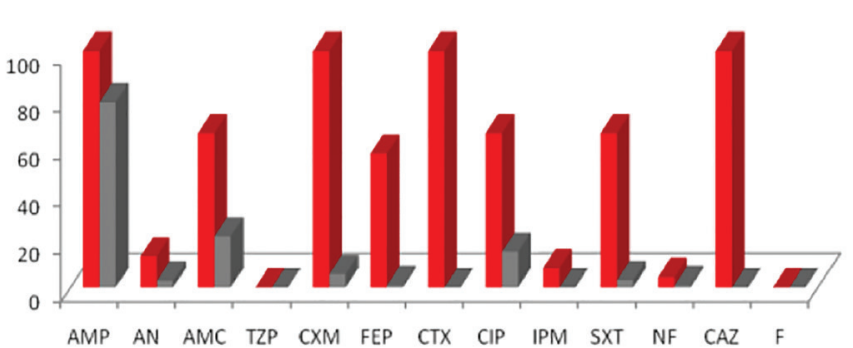

FIGURE I. Antimicrobial resistance rates of ESBL-EC and non-ESBLEC isolates

AMP: Ampicillin; AN: Amikacin; AMC: Amoxicillin/Clavulanic Acid; TZP: Piperacillin-Tazobactam; CXM: Cefuroxime; FEP: Cefepime; CTX: Cefotaxime; IMP: Imipenem; SXT: Trimethoprim-Sulfamethoxazole; F: Fosfomycin; NF: Nitrofurantoin; CAZ: Ceftazidime.

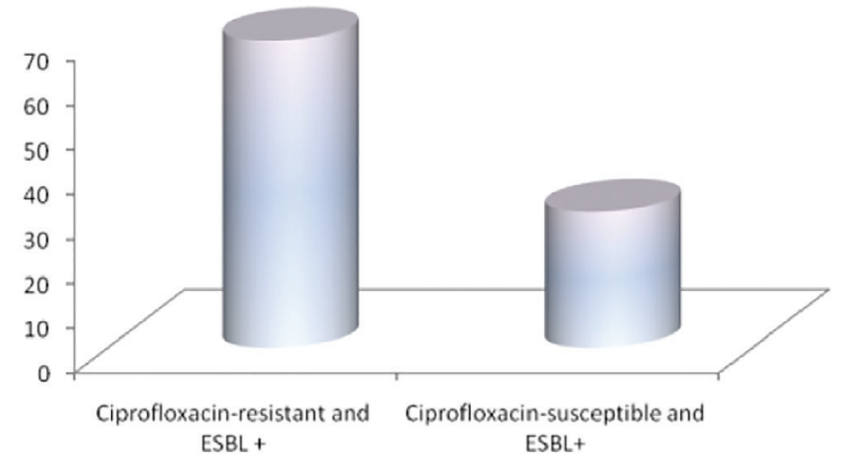

FIGURE 2. Percentage of ESBL production among CREC isolates ESBL production was significantly more frequent among ciprofloxacin-resistant E. coli isolates than among ciprofloxacin-susceptible isolates $(33 / 108)(p<0.0001)$.
PMQR gene-positive donors, recipients, and transconjugants using the E-test.

Quality control was performed using standard strains of $E$. coli ATCC 25922, ATCC 35218, Staphylococcus aureus ATCC 29213, and Pseudomonas aeruginosa ATCC 27853.

\section{Statistical Analysis}

The statistical analysis of the data was carried out using Fisher's exact test. A $p$-value of $p<0.05$ was accepted as statistically significant.

\section{RESULTS}

A total of 300 E. coli isolates were obtained from urine samples of outpatient women with symptoms suggestive of a UTI. The ESBL production was detected in $36 \%$ (108/300) of isolates.

\section{Antimicrobial Susceptibility Test}

The antimicrobial resistance rates were significantly higher in ESBL-producing E. coli (ESBL-EC) isolates than in non-ESBL-EC isolates $(p<0.05)$ (Figure I). Thirty-five percent $(105 / 300)$ were resistant to ciprofloxacin. Ciprofloxacin had MIC ranges of 0.008 to $\geq 32 \mu \mathrm{g} / \mathrm{mL}$ with MIC50 at $0.5 \mu \mathrm{g} / \mathrm{mL}$ and MIC90 at I $\mu \mathrm{g} / \mathrm{mL}$. Among the ESBL-EC isolates, ciprofloxacin resistance was determined at $69 \%(75 / 108)$. The ESBL production was significantly more frequent among ciprofloxacin-resistant E. coli (CREC) isolates than among ciprofloxacin-susceptible isolates (33/108) $(p<0.000$ l) (Figure 2). Sixty-five percent $(68 / 105)$ of CREC isolates belonged to women aged $>40$ years. Eight isolates were resistant to carbapenems, and the MICs of the isolates were determined $\geq 32 \mu \mathrm{g} / \mathrm{mL}$ for imipenem, meropenem, and ertapenem, and their carbapenemase activities were positive. These isolates were both resistant to ciprofloxacin and positive for ESBL production. One of the 8 isolates belonged to a 51 -yearold woman, and others belonged to young women (average 25 years old).

ESBL-CREC isolates were highly resistant to ampicillin, cefuroxime, cefotaxime, ceftazidime (I00\%), amoxicillin/clavulanic acid,

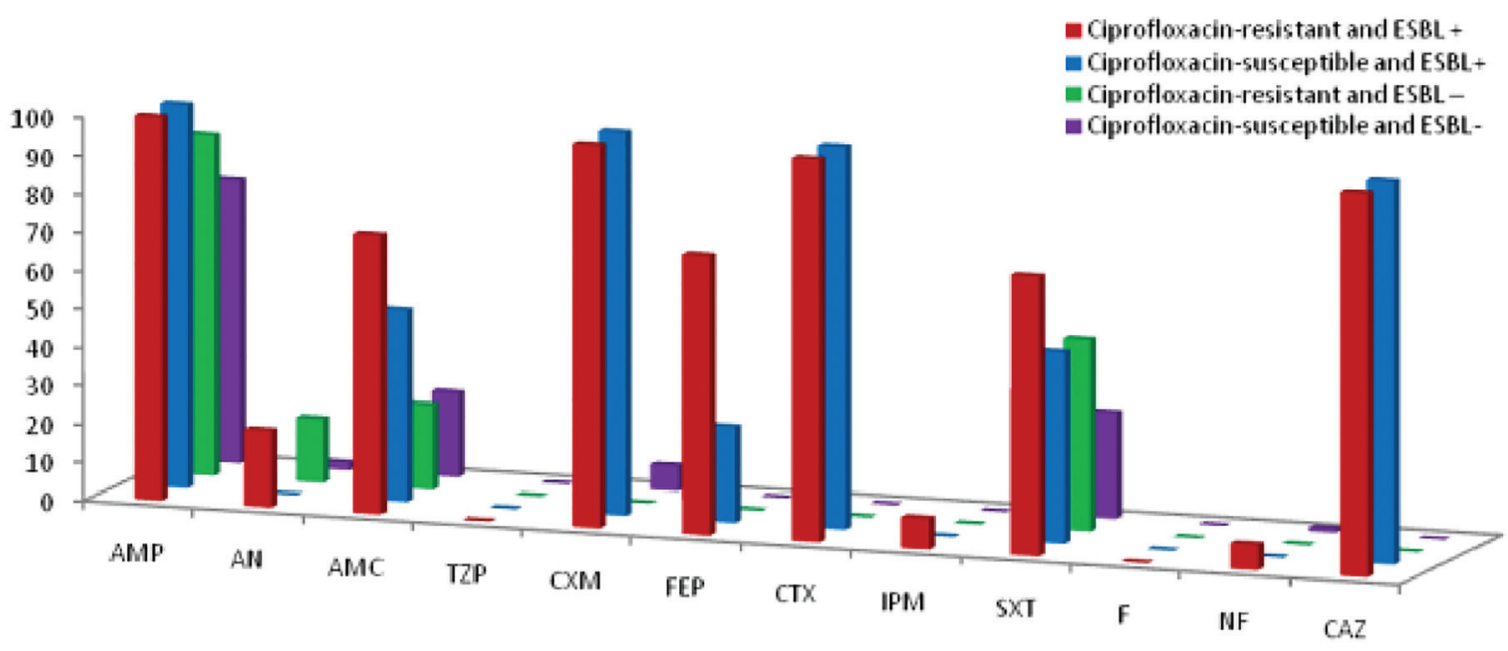

FIGURE 3. Antimicrobial resistance rates of $E$. coli isolates according to the presence or absence of ciprofloxacin resistance and ESBL production AMP: Ampicillin; AN: Amikacin; AMC: Amoxicillin/Clavulanic Acid; TZP: Piperacillin-Tazobactam; CXM: Cefuroxime; FEP: Cefepime; CTX: Cefotaxime; IMP: Imipenem; SXT: Trimethoprim-Sulfamethoxazole; F: Fosfomycin; NF: Nitrofurantoin; CAZ: Ceftazidime. 


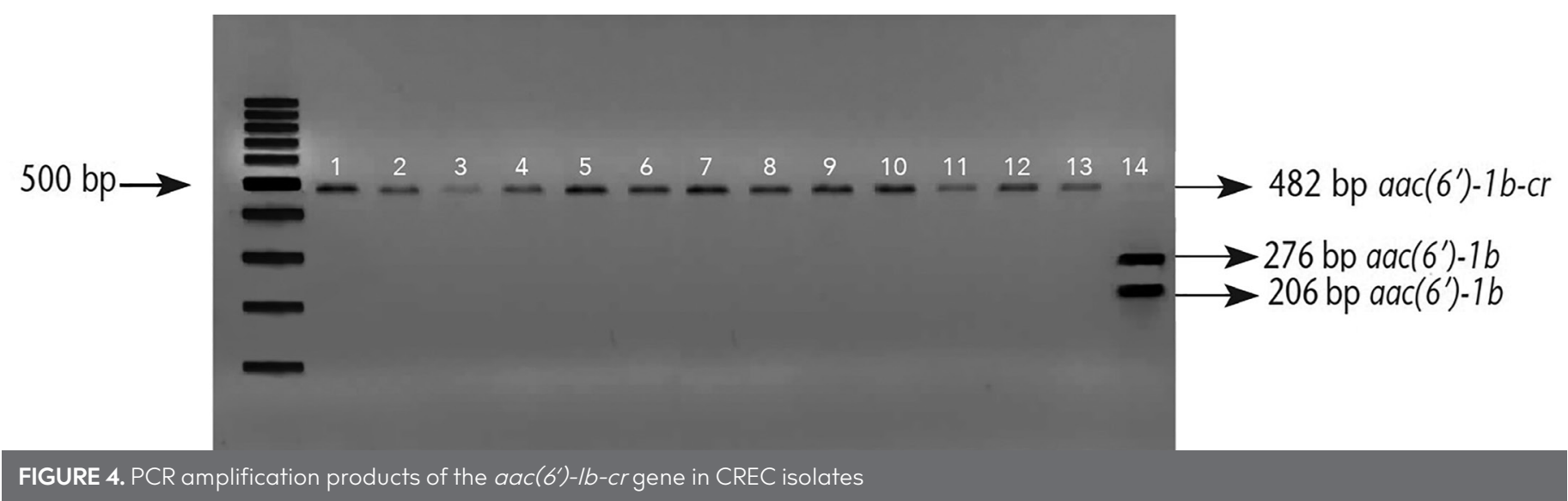

cefepime, and trimethoprim-sulfamethoxazole (73.3\%). The resistance was lower to amikacin (20\%) and nitrofurantoin (6.6\%) (Figure 3). The combined resistance to third-generation cephalosporins, carbapenems, ciprofloxacin, amikacin, trimethoprimsulfamethoxazole, and nitrofurantoin was detected in $2.6 \%$ $(8 / 300)$ of urine isolates. Fosfomycin, tigecycline, and colistin resistance was not detected in any of the isolates.

\section{Prevalence of PMQR Genes}

Forty percent (42/105) of CREC isolates were positive for aac ( $\left.66^{\prime}\right)$ $1 \mathrm{~b}$-cr variant, of which $50 \%$ (2l/42) were ESBL producers, and $28 \%(6 / 21)$ of these isolates were also resistant to carbapenems. None of the isolates harbored $q n r A$, $q n r B$, and qnrS genes.

\section{Conjugation Experiments}

Transconjugants (with plasmid sizes 54-100 kb) were successfully obtained from 6 of 42 aac ( $\left.6^{\prime}\right)$-lb-crgene-positive E. coliisolates used as donors. The aac ( $\left.6^{\prime}\right)$-lb-cr gene was successfully transferred from 6 aac $\left(6^{\prime}\right)$-lb-cr gene-positive E. coli urine isolates to their transconjugants. Transferability was 14\% (6/42) for $a a c\left(6^{\prime}\right)-/ b$-cr. E. coliisolates that harbored $a a c\left(6^{\prime}\right)-1 b$-crwere resistant to ciprofloxacin (MICs 32-256 $\mathrm{g} / \mathrm{mL}$ ). The MICs of ciprofloxacin for the 6 transconjugants ranged from 0.25 to I $\mu \mathrm{g} /$ $\mathrm{mL}$, or were 31 - to 125 -fold higher than that for the recipient $E$. coliJ53AzR (MIC $0.008 \mu \mathrm{g} / \mathrm{mL}$ ).

The PCR amplification products of aac (6')-lb-cr gene in CREC isolates are shown in Figure 4.

\section{DISCUSSION}

UTIs are the most common infections in women, and over $50 \%$ of women experience UTI at least once in their lifetime. UTI can significantly affect the quality of life. E. coli is the most common causative agent in the UTIs of women. These bacteria can easily become resistant. Many reports have shown that the prevalence of multidrug-resistant $E$. coli isolates is increasing worldwide because of the dissemination of mobile genetic elements (2l-24). A surveillance study conducted in Europe between 2004 and 20I0, including Turkey, reported that the ESBL production is positive in the mean $15 \%$ of $E$. coli isolates from different samples, and Turkey has the highest percentage with 25\% (23). In the present study, the ESBL production was $36 \%$ among the urine isolates of $E$. colifrom outpatient women patients.

An increase in quinolone resistance among ESBL-EC isolates has been reported all over the world. In an antimicrobial resis- tance surveillance study report on ECDC in 2012, the average percentage of resistance to quinolone was $22 \%$, and it was predominant in Italy and Cyprus (42\%), and Slovakia (4l\%) (2l), and in Turkey (52\%) (22). In a study conducted in our hospital in 2009, the rate of ciprofloxacin resistance among ESBL-EC blood isolates was $57.6 \%$ (24). In the present study, ciprofloxacin resistance was determined as 69\% (75/108) in ESBL-EC urine isolates. The ESBL production was significantly more frequent among our CREC isolates than among ciprofloxacin-susceptible isolates $(p<0.0001)$.

$P M Q R$ genes may facilitate the spreading and increase the prevalence of quinolone-resistant isolates. The aac( $\left.6^{\prime}\right)$-lb-crencodes a bifunctional aminoglycoside 6'-N-acetyltransferase capable of acetylating both aminoglycosides and fluoroquinolones (25). In the many studies conducted on $E$. coli in different countries, the frequency rates of the qnr gene were reported at rates $11 \%-75 \%$ (26-28). In studies conducted in Turkey, the most prevalent PMQR determinant was aac (6')- $/ b-c r$ (at rates $46 \%-60 \%$ ) (29-31). In the present study, we observed that the frequency of aac (6')-lb-cr was 40\% (42/105) in CREC isolates. Several studies demonstrated the association between aac $\left(6^{\prime}\right)$ $1 b-c r$ and the ESBL (3I-33). Similarly, we determined that 50\% of $E$. coli isolates harboring $a a c\left(6^{\prime}\right)-l b$-cr were ESBL producers. The conjugation experiments demonstrated that $a a c\left(6^{\prime}\right)-1 b$ cr was transferable. The MICs of ciprofloxacin for transconjugants harboring $a a c\left(6^{\prime}\right)-I b-c r$ were $31-$ to 125 - fold higher than the MIC for the recipient E. coli J53AzR. In conjugation experiments, we showed the possibility that the aac $\left(6^{\prime}\right)-l b-c r$ gene could be transferred horizontally among isolates of E. coli, causing uncomplicated community-acquired UTI in Turkish women.

Several reports of $E$. coli resistant to aminoglycosides are increasing worldwide $(21,22,24)$. The resistance to amikacin was reported as $11 \%$ for ESBL-EC in the United States (34). In the EARSS Annual Report, the resistance to aminoglycosides in $E$. coli isolated from different samples was 35\% in Turkey (22). In the current study, amikacin resistance was detected at $20 \%$ in urine isolates.

Carbapenems are also considered among the last-resort antibiotics in the treatment of serious infections caused by multidrug-resistant members of the Enterobacteriaceae, including $E$. coli. However, because of the global increase of carbapenem resistance, these bacteria have become a worldwide problem (2I). In the present study, 8 isolates were resistant to carbapen- 
ems (MICs $>32 \mu \mathrm{g} / \mathrm{mL}$ ). These isolates were both resistant to ciprofloxacin, and ESBL was positive.

The percentage of combined resistance to third-generation cephalosporins, fluoroquinolones, and aminoglycosides was $4 \%$ in Europe (2I). In the current study, the percentage of combined resistance, including carbapenems and nitrofurantoin among the ESBL-EC isolates in urine samples of women with symptoms suggestive of a community-acquired UTIs was $2.6 \%$.

Tigecycline was approved by the Food and Drug Administration (FDA) in 2005, and it, like "old" antibiotics, phosphomycin and colistin, is among the remaining options in clinical use for the treatment of UTIs caused by multidrug-resistant $E$. coli isolates (35). In the last decade, colistin has been increased for the treatment of multidrug-resistant Gram-negative bacilli, especially in combination with other drugs (35).

In the 2013 report by IDSA, ESBL-EC was listed among the 6 drug-resistant microbes urgently needed in new treatments (36). These data led to reconsidering nontraditional antibiotics such as fosfomycin, a phosphonic acid derivative approved by the FDA for the treatment of uncomplicated UTIs in women. Recent reports have shown that it has in vitro activity against multidrug-resistant pathogens, including $\operatorname{ESBL-CREC~}(37,38)$. As it was also seen in the present study, fosfomycin has shown good in vitro activity against ESBL-CREC isolates. It may be a promising treatment option. However, clinical data regarding the use of fosfomycin in the treatment of UTls caused by multidrug-resistant pathogens are still limited, and concerns about the widespread use of fosfomycin include tolerability, cost, and resistance (39). A recent analysis reports a fosfomycin resistance rate of $0.5 \%$ in community-acquired $E$. coli UTI in women in the United Kingdom (II). A systematic review of data, mainly from Europe and Asia, showed that $97 \%$ of ESBL-EC was susceptible to fosfomycin. Data from both in vitro and clinical studies are suggesting that fosfomycin should be used with caution in infections caused by ESBL-EC. In these studies, it is emphasized that the reason for the emergence of resistance to fosfomycin in ESBL-EC may be related to the increased use of this agent (37).

The ability of $E$. colito transfer resistance genes to other bacteria causes the spread of antimicrobial resistance. This situation threatens the effectiveness of existing antibiotics. High rates of recurrent UTIs suggest that antibiotics are not an effective therapy for all UTIs, and UTIs are resulting in billions of dollars in health care costs annually.

In conclusion, our findings indicate that the rates of ciprofloxacin resistance among urine isolates of $E$. coli in women are high, that CREC isolates carry a transferable aac ( $\left.6^{\prime}\right)$-lb-crgene, and that they have a combined drug resistance (2.6\%), including carbapenems of ESBL-EC urine isolates. These data point out that the multidrug resistance has the potential to spread among $E$. coli isolates from urine samples of outpatient women with community-acquired UTIs. We observed it had a low resistance for nitrofurantoin (6.6\%). None of our multidrug-resistant E. coliurine isolates showed resistance to fosfomycin, tigecycline, or colistin. There is a need for accurate epidemiological data for appropriate empirical treatment in patients with both the community and the hospital hospital-acquired infections in each country. Therefore, it is crucial to apply antimicrobial resistance prevention and control strategies to reduce morbidity, mortality, and health care costs; limit the potential spread of resistance genes; and ensure careful antibiotic use in UTIs caused by E. coliwith superbug potency.

Ethics Committee Approval: Ethics committee approval was received for this study from the Ethics Committee of the İstanbul University-Cerrahpașa, Cerrahpașa School of Medicine.

Informed Consent: Written informed consent was obtained from the patients who participated in this study.

Peer review: Externally peer reviewed

Author Contributions: Concept - S.Ö., O.A., A.Ö., I.H.Ç., F.K.C..; Design - S.Ö., O.A., A.Ö., I.H.C.., F.K.C..; Supervision - S.Ö., O.A., A.Ö., I.H.Ç., F.K.C..; Data Collection and/or Processing - S.Ö., O.A.; Analysis and/or Interpretation - S.Ö., O.A.; Literature Search - A.Ö., İ.H.C.., F.K.Ç.; Writing Manuscript - A.Ö., I.H.C.., F.K.C.; Critical Review - S.Ö., O.A., A.Ö., I.H.C.., F.K.C..

Conflict of Interest: The authors have no conflicts of interest to declare.

Financial Disclosure: The authors declared that this study has received no financial support.

\section{REFERENCES}

I. Kranz J, Schmidt S, Lebert C, Schneidewind L, Schmiemann G, Wagenlehner $F$. Uncomplicated bacterial community acquired urinary tract infection in adults. Dtsch Arztebl Int 2017; II4: 866-73. [Crossref]

2. Nordmann P, Poirel L. The difficult-to-control spread of carbapenemase producers among Enterobacteriaceae worldwide. Clin Microbiol Infect 2014; 20: 82I-30. [Crossref]

3. Strahilevitz J, Jacoby GA, Hooper DC, Robicsek A. Plasmid-Mediated Quinolone Resistance: A Multifaceted Threat. Clin Microbiol Rev 2009; 22: 664-89. [Crossref]

4. Martinez-Martinez L, Eliecer Cano M, Manuel Rodríguez-Martínez J, Calvo J, Pascual A. Plasmid-mediated quinolone resistance. Expert Rev Anti Infect Ther 2008; 6: 685-7II. [Crossref]

5. Redgrave LS, Sutton SB, Webber MA, Piddock LJ. Fluoroquinolone resistance: mechanisms, impact on bacteria, and role in evolutionary success. Trends Microbiol 2014; 22: 438-45. [Crossref]

6. Garoff L, Yadav K, Hughes D. Increased expression of Qnr is sufficient to confer clinical resistance to ciprofloxacin in Escherichia coli. J Antimicrob Chemother 2018; 73: 348-52. [Crossref]

7. Firoozeh F, Zibaei M, Soleimani-Asl Y. Detection of plasmid-mediated qnr genes among the quinolone-resistant Escherichia coli isolates in Iran. J Infect Dev Ctries 2014; 8: 818-22. [Crossref]

8. Poirel L, Rodriguez-Martinez JM, Mammeri H, Liard A, Nordmann $P$. Origin of plasmid-mediated quinolone resistance determinant QnrA. Antimicrob Agents Chemother 2005; 49: 3523-5. [Crossref]

9. Jiang $X, L i$ J, Zhang Y, Yan H, Wang Y, Shi L, et al. Detection of plasmid-mediated quinolone resistance determinants and qnrS expression in Enterobacteriaceae clinical isolates. J Infect Dev Ctries 2014; 8: 1625-9. [Crossref]

10. Grundmann H, Livermore DM, Giske CG, Canton R, Rossolini GM, Campos J, et al. Carbapenem-non-susceptible Enterobacteriaceae in Europe: conclusions from a meeting of national experts. Euro Surveill 2010; 15: I-13. [Crossref]

II. Matthews PC, Barrett LK, Warren S, Stoesser N, Snelling M, Matthew Scarborough $M$, et al. Oral fosfomycin for treatment of urinary tract infection: a retrospective cohort study. BMC Infect Dis 2016; 16: 556. [Crossref]

12. Concia E, Bragantini D, Mazzaferri F. Clinical evaluation of guidelines and therapeutic approaches in multi drug-resistant urinary tract infections. J Chemotherapy 2017; 29(SI): 19-28. [Crossref] 
13. Gupta K, Hooton TM, Naber KG, Wullt B, Colgan R, Miller LG, et al. International clinical practice guidelines for the treatment of acute uncomplicated cystitis and pyelonehritis in women: A 2010 update by the IDSA and European Society for Microbiology and Infectious Diseases. Clin Infect Dis 2011; 52: el03-20. [Crossref]

14. European Committee on Antimicrobial Susceptibility Testing (EUCAST). Breakpoint tables for interpretation of MICs and zone diameters. Version 9.0, 2019.

15. Nordmann P, Dortet L, Poirel L. Rapid detection of carbapenemase-producing Enterobacteriaceae. Emerg Infect Dis 2012; 18 : 1503-7. [Crossref]

16. Mushi MF, Mshana SE, Imirzalioglu C, Bwanga F. Carbapenemase genes among multidrug resistant gram-negative clinical isolates from a tertiary hospital in Mwanza, Tanzania. Biomed Res Int 2014; 1-6. 303104. [Crossref]

17. Maynard C, Bekal S, Sanschagrin F, Levesque RC, Brousseau R, Masson $L$, et al. Heterogeneity among virulence and antimicrobial resistance gene profiles of extraintestinal Escherichia coli isolates of animal and human origin. J Clin Microbiol 2004; 42: 5444-52. [Crossref]

18. Robicsek A, Jacoby GA, Hooper DC. The worldwide emergence of plasmid mediated quinolone resistance. Lancet Infect Dis 2006; 6: 629-40. [Crossref]

19. Wang M, Tran JH, Jacoby GA, Zhang Y, Wang F, Hooper DC. Plasmid-mediated quinolone resistance in clinical isolates of Escherichia coli from Shanghai, China. Antimicrob Agents Chemother 2003; 47: 2242-8. [Crossref]

20. Martinez-Martinez L, Pascual A, Jacoby GA. Quinolone resistance from a transferable plasmid. Lancet 1998; 351: 797-9. [Crossref]

21. European Centre for Disease Prevention and Control (ECDC). Antimicrobial resistance surveillance in Europe 2012, Annual Report of the European Antimicrobial Resistance Surveillance Network (EARS-Net). Stockholm, Sweden, ECDC; 2013.

22. European Antimicrobial Resistance Surveillance System. EARSS Annual Report 2008; EARSS: Bilthoven, The Netherland, 2009.

23. Balode A, Punda-Polic V, Dowzicky MJ. Antimicrobial susceptibility of gram-negative and gram-positive bacteria collected from countries in Eastern Europe: Results from the Tigecycline Evaluation and Surveillance Trial (T.E.S.T.) 2004-2010. Int J Antimicrob Agents 2013; 4l: 527-35. [Crossref]

24. Koksal F, Ak K, Kucukbasmaci O, Samasti M. Prevalence of antimicrobial resistance patterns of extended-spectrum beta-lactamase producing E. coli and K. pneumoniae isolated blood cultures in an Istanbul University Hospital. Chemother 2009; 55: 293-7. [Crossref]

25. Guillard T, Cambau E, Chau F, Massias L, de Champs C, Fantin B. Ciprofloxacin Treatment Failure in a Murine Model of Pyelonephritis Due to an AAC(6')-Ib-cr-Producing Escherichia coliStrain Susceptible to Ciprofloxacin In Vitro. Antimicrob Agents Chemother 2013; 57: 5830-5. [Crossref]

26. Longhi C, Conte MP, Marazzato M, lebba V, Totino V, Santangelo F, et al. Plasmid-mediated fluoroquinolone resistance determinants in Escherichia coli from community uncomplicated urinary tract infection in an area of high prevalence of quinolone resistance. Eur J Clin Microbiol Infect Dis 2012; 31: 1917-21. [Crossref]
27. Volcao LM, Lacava JP, Gewehr MF, Leal VL, Ramis IB, Ramos DF, et al. High frequency of the aac ( $\left.6^{\prime}\right)-\mathrm{lb}$-cr gene associated with double mutations in gyrA and parC in Escherichia coli isolates from patients with urinary tract infections. J Glob Antimicrob Resist 2018; 13: 180-3. [Crossref]

28. Goudarzi M, Fazeli M. Quinolone Resistance Determinants qnr, qep, and $\operatorname{aac}\left(6^{\prime}\right)-\mathrm{lb}-\mathrm{cr}$ in Extended-Spectrum B-Lactamase Producing Escherichia coli Isolated From Urinary Tract Infections in Tehran, Iran. Shiraz E-Med J 2017; 18: e44498. [Crossref]

29. Oktem IM, Gulay Z, Bicmen M, Gur D. HITIT Project Study Group: qnrA prevalence in extended-spectrum beta-lactamase-positive Enterobacteriaceae isolates from Turkey. Jpn J Infect Dis 2008; 6I: 13-7.

30. Nazik H, Bektöre B, Ongen B, Ilktac M, Ozyurt M, Kuvat N, et al. Plasmid-Mediated Quinolone Resistance Genes in Escherichia coli Urinary Isolates from Two Teaching Hospitals in Turkey: Coexistence of TEM, SHV, CTX-M and VEB-I Type-lactamases. Trop J Pharm Res 20II; 10: 325-33. [Crossref]

31. Aktepe OC, Așık G, Cetinkol Y, Biçmen M, Gülay Z. Investigation of plasmid-mediated quinolone resistance in Escherichia colistrains. Mikrobiyol Bul 2012; 46: 9-16.

32. Pitout JD, Wei $Y$, Church DL, Gregson DB. Surveillance for plasmid-mediated quinolone determinants in Enterobacteriacea within the Calgary Health Region, Canada: the emergence of aac( $\left.6^{\prime}\right)-l b-$ cr. J Antimicrob Chemother 2008; 61: 999-1002. [Crossref]

33. Yang HY, Nam YS, Lee HJ. Prevalence of plasmid-mediated quinolone resistance genes among ciprofloxacin-non susceptible Escherichia coli and Klebsiella pneumoniae isolated from blood cultures in Korea. Can J Infect Dis Med Microbiol 2014; 25: 163-9. [Crossref]

34. Bouchillon SK, Badal RE, Hoban DJ, Hawser SP. Antimicrobial susceptibility of inpatient urinary tract isolates of gram-negative bacilli in the United States: results from the study for monitoring antimicrobial resistance trends (SMART) program: 2009-20II. Clin Ther 2013; 35: 872-7. [Crossref]

35. Thadena JT, Pogueb JM, Kayec KS. Role of newer and re-emerging older agents in the treatment of infections caused by carbapenem-resistant Enterobacteriaceae. Virulence 2017; 8: 403-16. [Crossref]

36. Boucher HW, Talbot GH, Benjamin DK, Bradley J, Guidos RJ, Jones $\mathrm{RN}$, et al. $10 \times 20$ Progress-Development of New Drugs Active Against Gram-Negative Bacilli: An Update From the Infectious Diseases Society of America (IDSA Public Policy). Clin Infect Dis 2013; 56: 1685-94. [Crossref]

37. Neuner EA, Sekeres J, Hall GS, van Duin D. Experience with Fosfomycin for Treatment of Urinary Tract Infections Due to Multidrug-Resistant Organisms. Antimicrob Agents Chemother 2012; 56: 5744. [Crossref]

38. Karlowsky JA, Denisuik AJ, Lagacé-Wiensa PRS, Adam HJ, Baxter MR, Hoban DJ, et al. In Vitro Activity of Fosfomycin against Escherichia coli Isolated from Patients with Urinary Tract Infections in Canada as Part of the CANWARD Surveillance Study. Antimicrob Agents Chemother 2014; 58: 1252-6. [Crossref]

39. Tandogdu Z, Wagenlehner FM. Global epidemiology of urinary tract infections. Curr Opin Infect Dis 2016; 29: 73-9. [Crossref] 